\title{
Roscovitine, a CDK5 Inhibitor, Alleviates Sevoflurane-Induced Cognitive Dysfunction via Regulation Tau/GSK3 $\beta$ and ERK/PPARY/CREB Signaling
}

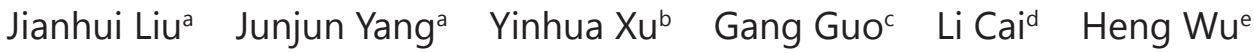 \\ Yanhong Zhao ${ }^{\mathrm{a}}$ Xiaoqing Zhang ${ }^{\mathrm{a}}$
}

aDepartment of Anesthesiology, Shanghai Tongji Hospital, Tongji Medical School, Tongji University , Shanghai, 'bepartment of Anesthesiology, Huadong Hospital Affiliated to Fudan University, Shanghai, 'Department of Emergency Internal Medicine, Shanghai Tongji Hospital, Tongji Medical School, Tongji University, Shanghai, dDepartment of Scientific Research Management, Shanghai Tongji Hospital, Tongji Medical School, Tongji University, Shanghai, e'Department of Psychology, Shanghai Tongji Hospital, Tongji Medical School, Tongji University, Shanghai, China

\author{
Key Words \\ Sevoflurane $\cdot$ Cognitive dysfunction $•$ CDK5 • Tau • PPAR $\gamma$
}

\begin{abstract}
Background/Aims: Multiple exposures to anesthesia in children may increase the risk of developing cognitive impairment. Sevoflurane is an anesthetic that is commonly used in children during surgery. Cyclin-dependent kinase (CDK) 5 is involved in the regulation of sevoflurane-induced cognitive dysfunction, but the mechanistic details remain unclear. The present study evaluated the mechanism by which CDK5 mediates sevoflurane-induced cognitive dysfunction in mice. Methods: Hippocampal neurons were isolated from postnatal day 0 C57BL/6 mouse pups. Six-day-old wild-type mice were exposed to sevoflurane and then treated with the CDK5 inhibitor roscovitine. The effects on cognitive function were evaluated with the Morris water maze and neuronal damage in the hippocampus was assessed by immunohistochemical analysis. Results: CDK5 activation increased neuronal damage by inducing Tau/glycogen synthase kinase (GSK) $3 \beta$ and suppressing extracellular signal-regulated kinase (ERK)/peroxisome proliferator-activated receptor (PPAR)y/cyclic AMP response element-binding protein (CREB) signaling following exposure to sevoflurane. CDK5 inhibition by roscovitine administration alleviated sevoflurane-induced neuronal damage and cognitive impairment. Conclusions: Inhibiting CDK5 with roscovitine has neuroprotective effects against neuronal injury and cognitive dysfunction caused by sevoflurane anesthesia that are exerted via modulation of Tau/GSK3 $\beta$ and ERK/PPAR $\gamma / C R E B$ signaling.
\end{abstract}




\section{Introduction}

General anesthetics can be neurotoxic to the developing brain [1-4], which is a major concern for children undergoing surgery. Multiple exposures to anesthesia, especially at an early age, can cause learning disabilities in children $[5,6]$.

The hippocampus plays a central role in learning and memory [7]. Sevoflurane (2, 2,2-trifluoro-1-[trifluoromethyl] ethyl fluoromethyl ether) is one of the most frequently used volatile anesthetics for induction and maintenance of general anesthesia during surgery owing to its low blood-gas partition coefficient and low pungency [8]. Sevoflurane can easily cross the blood-brain barrier and affect central nervous system function [9]; in fact, sevoflurane-induced toxicity has been shown to cause cognitive dysfunction in the developing brain [9-11].

Cyclin-dependent kinase (CDK)5 is a serine/threonine protein kinase that forms complexes with p35 or p39 and is essential for neural development and function [12]. Downregulation of CDK5 has been shown to mitigate hippocampal degeneration and cognitive dysfunction. CDK5 inhibition activates cyclic AMP response element-binding protein (CREB), peroxisome proliferator-activated receptor (PPAR) $\gamma$, and extracellular signal-regulated kinase (ERK), which are important factors modulating neuronal plasticity [13-15]. Sevoflurane-induced cognitive dysfunction has been linked to Tau phosphorylation by CDK5; this activates glycogen synthase kinase (GSK) $3 \beta$, leading to upregulation of proinflammatory cytokines and neuronal damage $[8,16,17]$.

The present study investigated the role of CDK5 in sevoflurane anesthesia-induced cognitive dysfunction in vitro and in vivo. We hypothesized that inhibiting CDK5 with roscovitine would alleviate sevoflurane-induced cognitive deficits and neuronal damage. We also examined the relationship between CDK5 and Tau/GSK3 $\beta$ and ERK/PPAR $\gamma /$ CREB signaling pathways in this process.

\section{Materials and Methods}

\section{Animals}

Animal experiments were approved by the Shanghai Tongji University School of Medicine Animal Care and Use Committee (Shanghai, China) and were performed in accordance with the National Institutes of Health (NIH) Guide for the Care and Use of Laboratory Animals (Department of Health and Human Services, NIH Publication No. 86-23, revised 1985).

Pregnant mice were obtained from the Fudan University Animal Care Committee and were individually housed under standard laboratory conditions (12:12-h light/dark cycle, $22{ }^{\circ} \mathrm{C}, 60 \%$ humidity) with free access to tap water and food. Animals were allowed to adapt to the laboratory environment for at least 3 weeks prior to experiments.

\section{Anesthesia exposure and ethics statement}

Seven-day-old mice were used for experiments. Littermates were randomly divided into sevoflurane treatment and air-only control groups. Mice in the treatment group were exposed to $2.2 \%$ sevoflurane $(\sim 1.0$ minimum alveolar concentration) for $2 \mathrm{~h}$ /day on 3 consecutive days. Anesthetic, $\mathrm{O}_{2}$, and $\mathrm{CO}_{2}$ concentrations in the chamber were continuously monitored (GE Datex 5 Ohmeda; Soma Technology, Tewksbury, MA, USA). A warming blanket was used to maintain body temperature between $37^{\circ} \mathrm{C}$ and $38^{\circ} \mathrm{C}$. Mice were returned to their cages after recovery. There was no mortality during administration of anesthesia or in the subsequent 2 weeks. After three consecutive doses of anesthetic, some mice in each group were euthanized with pentobarbital, and their brains were extracted and frozen in liquid nitrogen for protein and mRNA analysis. The remaining mice in each group were tested for learning and memory function when they reached the appropriate age.

To assess the role of CDK5 in sevoflurane-induced injury of hippocampal neurons, mice were intraperitoneally injected with the CDK5 inhibitor roscovitine $(25 \mathrm{mg} / \mathrm{kg})$ before sevoflurane anesthesia. 


\section{Cellular Physiology Cell Physiol Biochem 2017;44:423-435 \begin{tabular}{l|l|l} 
and Biochemistry 10.1159/000485008 & $\begin{array}{l}\text { (c) } 2017 \text { The Author(s). Published by S. Karger AG, Basel } \\
\text { www.karger.com/cpb }\end{array}$
\end{tabular}}

Liu et al.: The Effect of CDK5 to Sevoflurane-Induced Cognitive Dysfunction

\section{Morris water maze (MWM) test}

Learning and memory function was tested with the MWM as previously described [18]. Testing was carried out by an operator blinded to the treatment groups. The apparatus consisted of a round steel pool (diameter: $122 \mathrm{~cm}$; height: $60 \mathrm{~cm}$ ) that was filled with water to a level $1 \mathrm{~cm}$ higher than the top of a platform (diameter: $10 \mathrm{~cm}$; depth: $30 \mathrm{~cm}$ ). The pool was surrounded by a blue curtain with cues and was located in an isolated room $\left(20^{\circ} \mathrm{C}, 60 \%\right.$ humidity). The water was maintained at $21^{\circ} \mathrm{C}$ and opacified by adding titanium dioxide.

Testing was initiated on postnatal day 40-or day 34 from the beginning of sevoflurane exposure-and was continued for 5 days. The first four days (P40-P43) comprised a place navigation (reference memory) test consisting of 16 training trials (four trials per day for 4 days, with an inter-trial interval of 30-40 min). At the beginning of each trial, animals were placed in the water facing the wall at different starting positions (north, south, east, or west) and were allowed $60 \mathrm{~s}$ to find and $15 \mathrm{~s}$ to stay on the hidden platform. If the animal failed to locate the platform within $60 \mathrm{~s}$, it was guided to and allowed to stay on the platform for $15 \mathrm{~s}$. A video tracking system was used to record the swimming activity of each animal. Escape latency (i.e., time from placement into the water to staying on the platform) was recorded. On the fifth day (day 44), a spatial probe test was performed in which the platform was removed from the pool. The mouse was placed in the opposite quadrant and allowed to swim freely for $120 \mathrm{~s}$. The number of platform crossings was recorded. Data were analyzed using motion-detection software designed for the MWM test (Shanghai Mobile Datum Information Technology Co., Shanghai, China).

\section{Drug treatment}

Hippocampal neurons were treated with the CDK5 inhibitor roscovitine $(10 \mu \mathrm{M}$; Sigma-Aldrich, St. Louis, MO, USA, cat. no. R7772) and activator p35 (15 $\mu \mathrm{M}$; Dharmacon, Lafayette, CO, USA), and ERK1/2 inhibitor U0126 (50 nM; Sigma-Aldrich, cat. no. U120). Cells in each group were treated for $72 \mathrm{~h}$ and then harvested for analyses. Dimethyl sulphoxide (DMSO) was used as a control.

\section{Cell culture and treatment}

Primary hippocampal neuronal cultures were established as previously described [19]. Briefly, the hippocampus was isolated from postnatal day $0 \mathrm{C} 57 \mathrm{BL} / 6$ mice pups, cut into small pieces, and then digested with $0.125 \%$ trypsin for $15 \mathrm{~min}$ at $37^{\circ} \mathrm{C}$. After trituration and centrifugation, cells were seeded in poly-Dlysine $(10 \mathrm{mmol} / \mathrm{l})$-coated $10-\mathrm{mm}$ dishes at a density of $1 \times 10^{6} \mathrm{cells} / \mathrm{ml}$ and maintained in Neurobasal medium supplemented with 2\% B27 and 0.25\% Glumax (all from Gibco, Grand Island, NY, USA). After 3 days, $2.5 \mathrm{\mu g} / \mathrm{ml}$ cytosine arabinoside (Sigma-Aldrich) was added to the culture medium for $24 \mathrm{~h}$ to inhibit the proliferation of glia. Half of the total volume of medium was replaced every third day. Cells were maintained at $37{ }^{\circ} \mathrm{C}$ and $5 \% \mathrm{CO}_{2}$ for 14 days prior to experiments.

To mimic the conditions of sevoflurane anesthesia in vitro, the low-glucose Dulbecco's modified Eagle's medium used for hippocampal neuron cultures was replaced with glucose-free Neurobasal medium supplemented with $1 \% \mathrm{~B} 27$ and $2.78 \mathrm{mmol} / \mathrm{l}$ glucose. Cells were incubated with different concentrations of sevoflurane $(0,1 \%, 2 \%, 4 \%$, and $6 \%)$ for $6 \mathrm{~h}$ with/without roscovitine $(10 \mu \mathrm{M})$. The neurons were cultured under normal conditions for $24 \mathrm{~h}$ and were identified by immunocytochemical detection of enolase.

\section{Western blot analysis}

Cell and mouse hippocampal tissue lysates were separated in parallel on 10\% denaturing sodium dodecyl sulfate polyacrylamide gels. Proteins were transferred to a nitrocellulose membrane that was blocked with $5 \%$ non-fat milk in $0.1 \%$ Tris-buffered saline with Tween- 20 and incubated at $4{ }^{\circ} \mathrm{C}$ overnight with mouse monoclonal anti-CDK5 (1:100; cat. no. ab115812), anti-phospho-Y15 Tau (1:100; cat. no. ab133463), rabbit polyclonal anti-ERK1+ERK2 (1:100; cat. no. ab17942), and rabbit polyclonal anti-ERK1 (phospho Y204)+ERK2 (phospho Y187) (1:100; cat. no. ab47339), anti-phospho-S262 Tau (1:100; cat. no. ab64193) antibodies from Abcam (Cambridge, MA, USA). Anti-phospho-S112 PPAR $\gamma$ antibodies from Millipore (1:100; cat. no. 04-816), anti-PPAR $\gamma$ antibodies from Santa Cruz Biotechnology (California, USA) (1:100; cat. no. sc7273). Anti-phospho-S133 CREB-1 antibodies (1:100; cat. no. sc-81486), anti-CREB-1 antibodies (1:100; cat. no. sc-58), anti-BDNF antibodies (1:100; cat. no. sc-546), anti-PSD-95 antibodies (1:100; cat. no. sc71935), anti-Synapsin 1 antibodies (1:100; cat. no. sc-376623), anti-GSK-3 $\beta$ antibodies (1:100; cat. no. sc-71188), anti-phospho-S9 GSK-3 $\beta$ antibodies (1:100; cat. no. sc-24563), anti-Tau antibodies (1:100; cat. 


\section{Cellular Physiology Cell Physiol Biochem 2017;44:423-435 \begin{tabular}{l|l|l} 
and Biochemistry.1159/000485008 & $\begin{array}{l}\text { (C) 2017 The Author(s). Published by S. Karger AG, Basel } \\
\text { www.karger.com/cpb }\end{array}$
\end{tabular}}

Liu et al.: The Effect of CDK5 to Sevoflurane-Induced Cognitive Dysfunction

no. sc-515539), anti-caspase-3 antibodies (1:100; cat. no. sc-1224), anti-Bax antibodies (1:100; cat. no. sc6236), anti-Bcl-2 antibodies (1:100; cat. no. sc-509) from Santa Cruz Biotechnology (California, USA). After washing, the membrane was incubated for $1 \mathrm{~h}$ at room temperature with horseradish peroxidase-labeled anti-rabbit/mouse IgG (Invitrogen, Carlsbad, CA, USA) at 1:3000 dilution. The supersignal-enhanced chemoluminescent substrate (Pierce Biotechnology, Rockford, IL, USA) was applied to the membrane and exposed for 10 min to visualize the protein bands (Super Rx; Fujifilm, Tokyo, Japan).

Terminal deoxynucleotidyl transferase dUTP nick end labeling (TUNEL) assay

Animals were sacrificed and transcardially perfused with ice-cold phosphate-buffered saline (PBS) followed by $4 \%$ paraformaldehyde and the brain was removed and embedded in paraffin. Coronal sections (5 $\mu \mathrm{m}$ thickness) were cut and stained using a TUNEL kit (Roche, Basel, Switzerland) according to the manufacturer's protocol. TUNEL-positive apoptotic cells (dark brown) were observed by light microscopy and counted by an investigator blinded to the group assignment. A reticle was used to count cells in five areas of the same size in different locations. The counts were averaged and are presented as the density of TUNEL-positive cells for each animal. The fraction of apoptotic neurons in cultures was similarly determined with the TUNEL assay.

\section{Cell viability assay}

The effect of sevoflurane on hippocampal neuronal viability was evaluated with the 3-(4, 5-dimethylthiazol-2-yl)-2, 5-diphenyltetrazolium bromide (MTT) assay. Neurons were treated with sevoflurane $(0,1 \%, 2 \%, 4 \%$, and $6 \%)$ for $6 \mathrm{~h}$ and then seeded in 96-well microtiter plates for $24 \mathrm{~h}$. At predetermined time points, $20 \mu \mathrm{l}$ MTT were added to each well for $4 \mathrm{~h}$. To determine the effect of CDK5 inhibition, $10 \mathrm{mM}$ roscovitine was added before sevoflurane treatment. The medium was discarded, and $150 \mu \mathrm{l}$ DMSO were added to each well for $20 \mathrm{~min}$. Optical density (OD) at $492 \mathrm{~nm}$ was measured and the rate of inhibition of proliferation was calculated as (1 - OD of experimental group/OD of control group) $\times 100 \%$. The experiment was repeated three times.

\section{Immunocytochemistry}

Hippocampal cells or tissue samples were incubated overnight with antibodies against neuron-specific enolase or CDK5 followed by fluorophore-conjugated secondary antibody for $1 \mathrm{~h}$ at room temperature in the dark. After several washes with PBS, samples were incubated with Hoechst33342 for 3 min and then mounted in glycerol and visualized under an epifluorescence microscope.

\section{Statistical analysis}

Continuous variables are presented as mean \pm SD. Multiple comparisons were carried out by one-way analysis of variance using Prism v.5.0 software (GraphPad Inc., La Jolla, CA, USA). Differences with a P value $\leq 0.05$ were considered statistically significant.

\section{Results}

\section{Sevoflurane toxicity in primary cultured hippocampal neurons}

After 9-14 days in culture, hippocampal neurons clustered and had good refractive power under an inverted microscope. The cell body was initially stellate before assuming a round, fusiform, or conical shape. Neuronal processes were apparent and a dense neuronal network eventually covered the culture dish (Fig. 1A). A combination of neuron-specific enolase and Hoechst33342 staining identified the cells as hippocampal neurons (Fig. 1B). The purity of the culture was confirmed by counting the number of neuron-specific enolasepositive cells per field/total cell number (Fig. 1B). To assess the toxicity of sevoflurane to hippocampal neurons, cells were treated with varying doses of sevoflurane $(0,1 \%, 2 \%, 4 \%$, and 6\%) for $6 \mathrm{~h}$ and viability was determined with the MTT assay. Viability was reduced by treatment with sevoflurane concentrations greater than $1 \%(P<0.001)$ and the effect was concentration-dependent. Exposure to $4 \%$ sevoflurane for $6 \mathrm{~h}$ reduced viability by almost $50 \%$ (Fig. 2A). 
Fig. 1. Primary culture and purity of hippocampal neurons (scale bars: 20 $\mu \mathrm{m})$. (A) Normal hippocampal neurons after 7 days in culture. (B) Verification

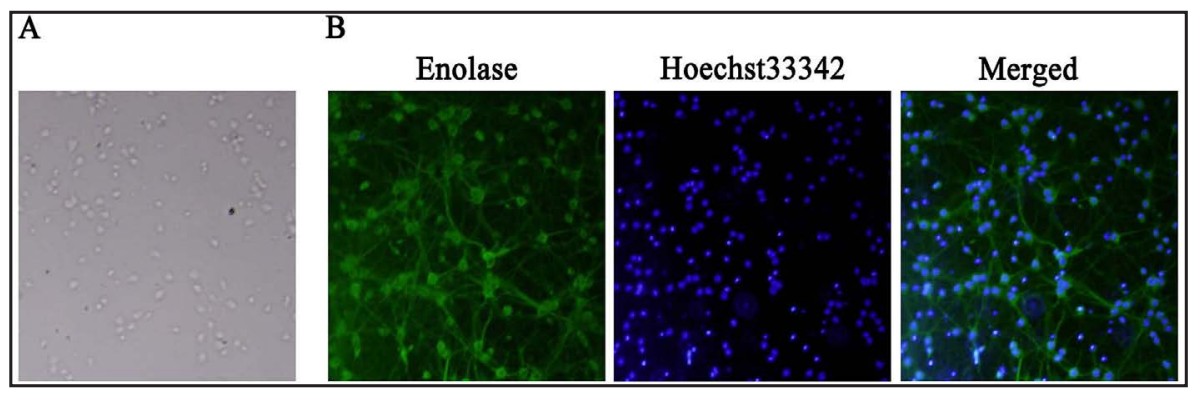
of hippocampal culture purity by immunofluorescence analysis of neurons were labeled with neuron-specific enolase (NSE, green). Nuclei were labeled with Hoechst33342 (blue).

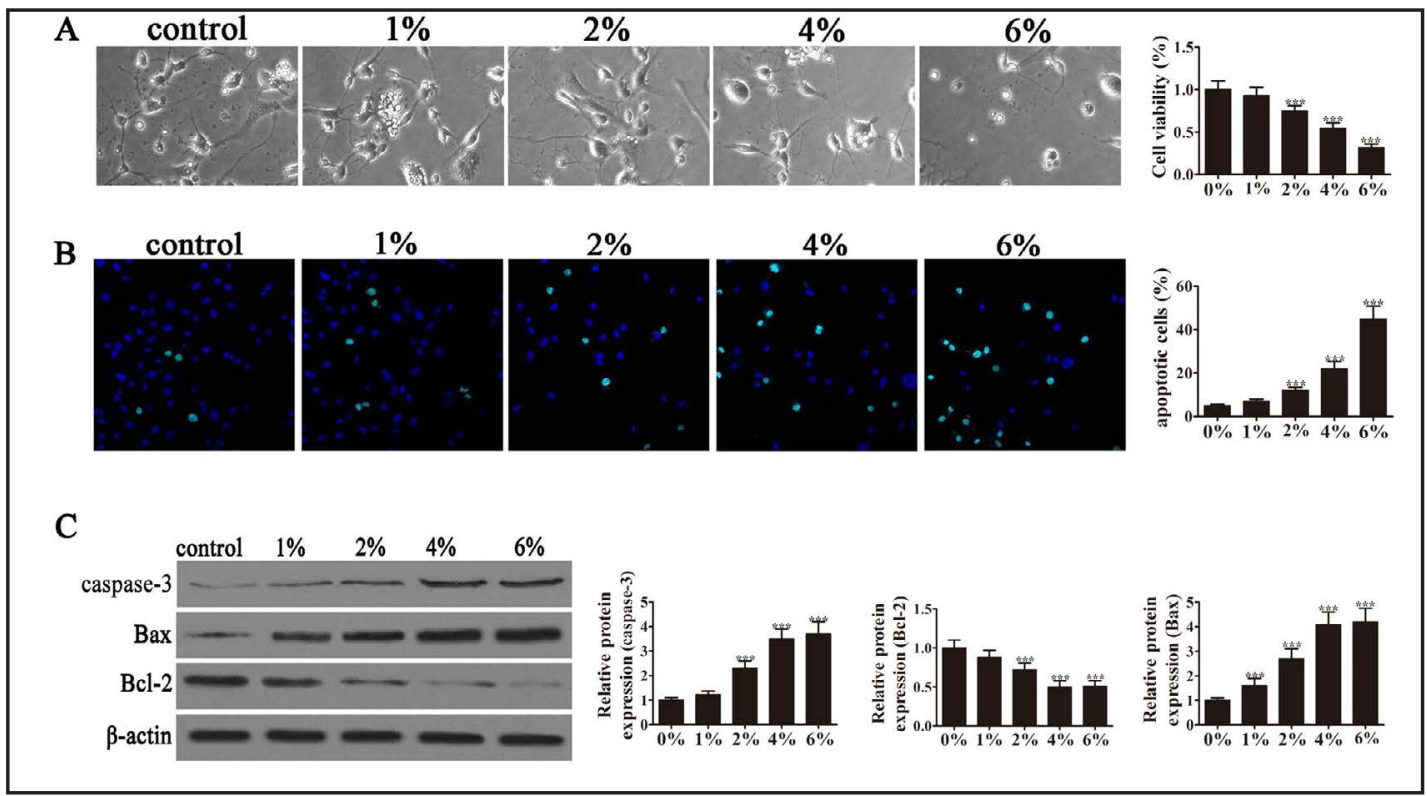

Fig. 2. Effect of sevoflurane on cultured primary hippocampal neurons. Neurons were treated with sevoflurane $(0,1 \%, 2 \%, 4 \%$, or $6 \%)$ for $6 \mathrm{~h}$ and viability and apoptosis were analyzed. (A) Evaluation of cell viability with the MTT assay. Sevoflurane treatment decreased viability in a dose-dependent manner. Values represent mean $\pm \operatorname{SD}(n=5)$. ${ }^{* * *} \mathrm{P}<0.001$ vs. Control (0\%). (B) Effect of sevoflurane on neuronal apoptosis. Results of the TUNEL assay are shown as a percentage of total cell counts. Values represent mean \pm SD (n $=10)$. ${ }^{* * *} \mathrm{P}<0.001$ vs. control. (C) Expression of apoptosis-related proteins Bcl-2, Bax, and caspase-3, as determined by western blotting. $\beta$-Actin was used as a loading control. Data represent mean $\pm \operatorname{SD}(n=3)$. $* * * \mathrm{P}<0.001$ vs. control.

To further clarify the neurotoxic effects of sevoflurane, primary hippocampal neurons were double-stained with fluorescein diacetate/propidium iodide to detect apoptotic cells. The number of apoptotic cells increased with sevoflurane concentration (Fig. 2B): exposure to $4 \%$ sevoflurane induced apoptosis in $20 \%$ of neurons $(\mathrm{P}<0.001)$. A western blot analysis revealed that expression of the pro-apoptotic proteins caspase- 3 and $\mathrm{B}$ cell lymphoma (Bcl)2 -associated X protein (Bax) increased with sevoflurane concentration, although no further changes were observed at concentrations higher than $4 \%$. The anti-apoptotic protein Bcl-2 showed the opposite trend (Fig. 2C).

ERK/PPAR /CREB signaling is involved in sevoflurane induced neuronal damage

ERK-mediated PPAR $\gamma /$ CREB signaling plays an important role in neuronal apoptosis under conditions of stress $[20,21]$. To determine whether the cytotoxic effects of sevoflurane are exerted via ERK/PPAR $\gamma /$ CREB signaling, cultured hippocampal neurons were pretreated 
Fig. 3. ERK/ PPAR $\gamma /$ CREB signaling is involved in sevofluraneinduced neuronal damage. Neurons were pretreated with the PPAR $\gamma$ agonist rosiglitazone (Rosi, $5 \mu \mathrm{M}$ ) for $24 \mathrm{~h}$ before treatment with $4 \%$ sevoflurane for 6 $\mathrm{h}$ or with the ERK1/2 inhibitor U0126 $(10 \mu \mathrm{M})$ for 24 h. (A) Sevoflurane induced cell damage by inhibiting ERK, PPAR $\gamma$, and CREB phosphorylation, as determined by western blotting. ERK1/2 inhibition had a similar effect to sevoflurane treatmen $\mathrm{t}$. Data represent mean \pm SD (n = 3). $* \mathrm{P}<0.05$, $* * * \mathrm{P}<0.001$ vs. control. PPAR $\gamma$ plays an important role in sevoflu-
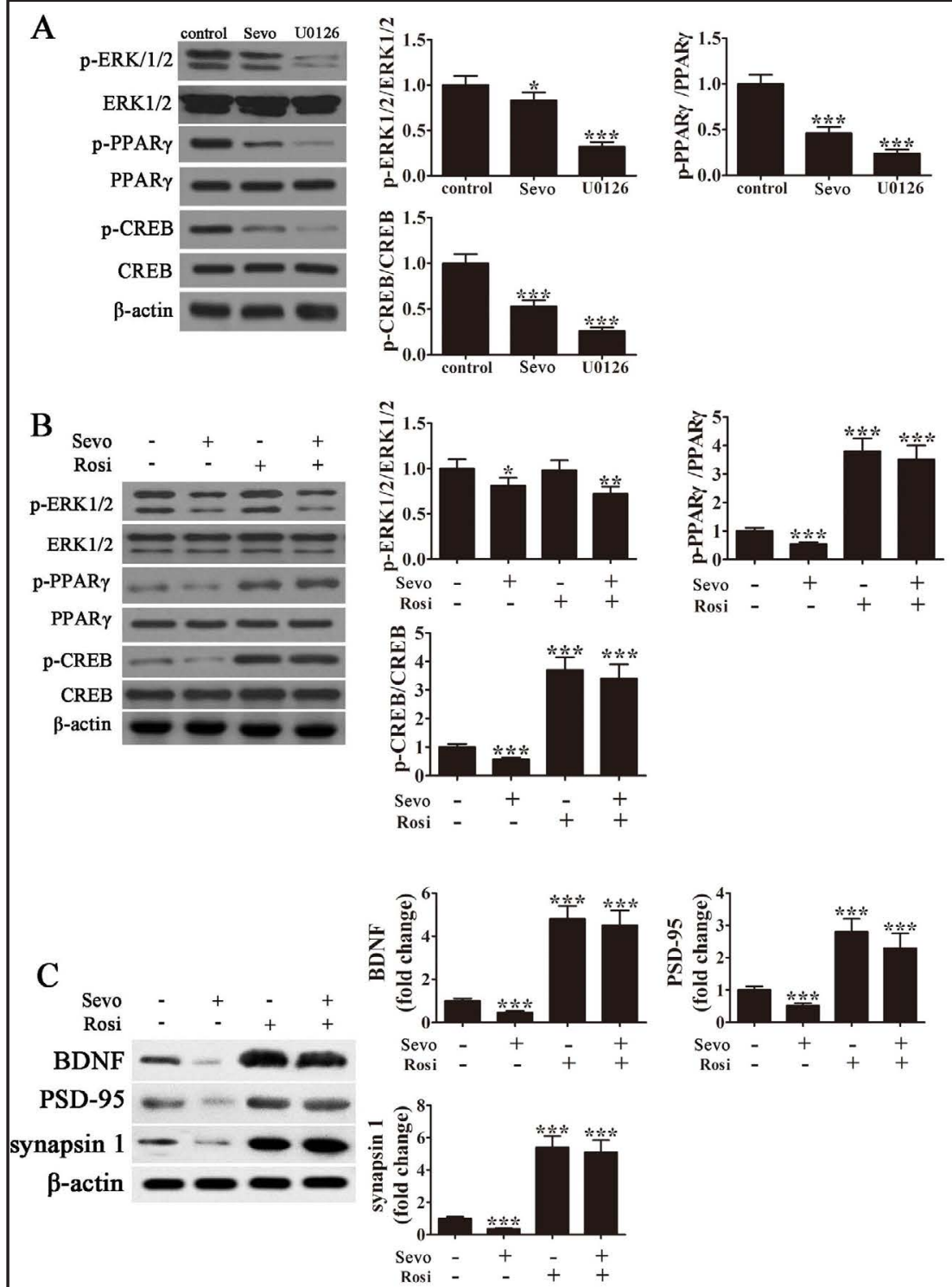

\section{$\mathrm{D}$}

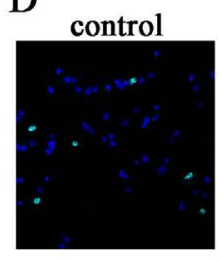

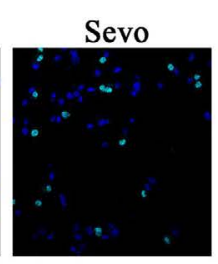
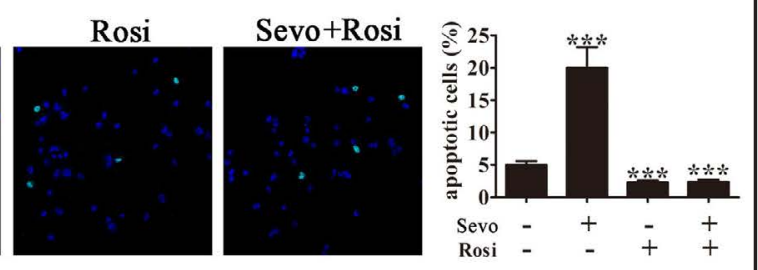

rane-induced and ERK1/2-mediated neuronal damage. Data represent mean $\pm \mathrm{SD}(\mathrm{n}=3) .{ }^{*} \mathrm{P}<0.05,{ }^{* *} \mathrm{P}<0.01$, ${ }^{* * *} \mathrm{P}<0.001$ vs. control. (C) CREB phosphorylation and BDNF, PSD-95, and synapsin 1 expression. Data represent mean $\pm \mathrm{SD}(\mathrm{n}=3)$. ${ }^{* * *} \mathrm{P}<0.001$ vs. control. (D) Neuronal apoptosis, as detected with the TUNEL assay. Values represent mean $\pm \mathrm{SD}(\mathrm{n}=10)$. ${ }^{* * *} \mathrm{P}<0.001$ vs. control.

with the PPAR $\gamma$ agonist rosiglitazone $(5 \mu \mathrm{M})$ for $24 \mathrm{~h}$ before $4 \%$ sevoflurane treatment for 6 $\mathrm{h}$, or with the ERK1/2 inhibitor U0126 $(10 \mu \mathrm{M})$ for $24 \mathrm{~h}$. Sevoflurane treatment suppressed ERK1/2, PPAR $\gamma$, and CREB phosphorylation, whereas U0126 treatment inhibited the phosphorylation of PPAR $\gamma$ and CREB (Fig. 3A). These results suggest that PPAR $\gamma$ and CREB activation via phosphorylation is regulated by ERK1/2. To clarify whether CREB is regulated 


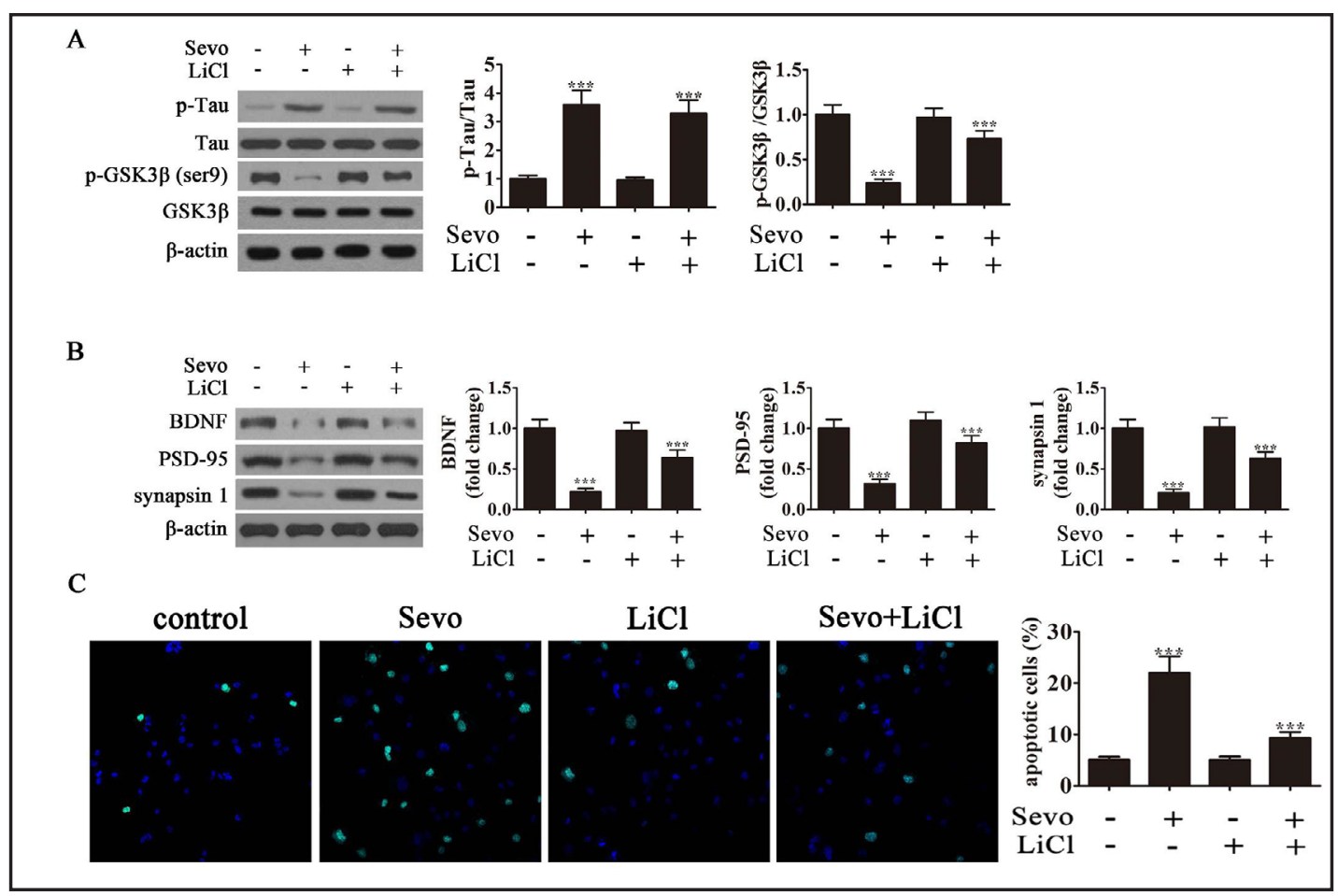

Fig. 4. Inhibition of Tau/GSK3 $\beta$ signaling abrogates sevoflurane-induced cell damage. Neurons were pretreated with $50 \mathrm{mM}$ GSK3 $\beta$ inhibitor (lithium chloride, LiCl) for $24 \mathrm{~h}$ before $4 \%$ sevoflurane treatment for $6 \mathrm{~h}$. (A) Expression of phosphorylated Tau, GSK3 $\beta$, and apoptosis-related proteins was detected by western blotting; $\beta$-actin was used as a loading control. Blocking GSK3 $\beta$ activation abolished sevofluraneinduced and Tau-mediated cell apoptosis. Data represent mean $\pm \mathrm{SD}(\mathrm{n}=3)$. ${ }^{* * *} \mathrm{P}<0.001$ vs. control. (B) Expression of BDNF, PSD-95, and synapsin 1, as determined by western blotting. Data represent mean \pm SD $(\mathrm{n}=3) .{ }^{* *} \mathrm{P}<0.001$ vs. control. (C) Neuronal apoptosis was detected with the TUNEL assay. Values represent mean $\pm \mathrm{SD}(\mathrm{n}=10) .{ }^{* * *} \mathrm{P}<0.001$ vs. control.

by PPAR $\gamma$, cells were treated with the PPAR $\gamma$ agonist rosiglitazone, which increased CREB phosphorylation while having no effect on ERK1/2. Rosiglitazone also relieved sevofluraneinduced suppression of PPAR $\gamma$ and CREB phosphorylation (Fig. 3B) and alleviated sevoflurane-induced synaptic dysfunction by enhancing the expression of synapsin-1, brainderived neurotrophic factor (BDNF), and postsynaptic density (PSD)95 (Fig. 3C), consistent with previous findings [22-24]. PPAR $\gamma$ activation by rosiglitazone treatment also decreased the apoptotic ratio that was increased by exposure to sevoflurane (Fig. 3D).

\section{Tau/GSK3 $\beta$ signaling is involved in sevoflurane-induced neuronal damage}

Sevoflurane has been shown to induce Tau phosphorylation and GSK3 $\beta$ activation in young mice, resulting in cognitive impairment [17]. A western blot analysis revealed that sevoflurane anesthesia increased Tau phosphorylation and activation but decreased the p-GSK3 $\beta$ (Ser9)/GSK3 $\beta$ ratio due to a decrease in GSK3 $\beta$ phosphorylation at serine 9 , which is known to activate GSK3 $\beta$. LiCl treatment suppressed GSK3 $\beta$ activation by increasing phosphorylation at serine 9 (Fig. 4A); this was accompanied by an increase in synapsin-1, BDNF, and PSD95 levels (Fig. 4B). LiCl also abolished sevoflurane-induced neuronal apoptosis (Fig. 4C). These findings suggest that inhibiting Tau/GSK3 $\beta$ signaling provides neuroprotection against the cytotoxic effects of sevoflurane.

\section{CDK5 modulates Tau/GSK3 $\beta$ and ERK/PPAR $/$ CREB signaling}

CDK5 plays an important role in memory formation [25]. We therefore speculated that CDK5 modulates sevoflurane-induced cognitive impairment. Sevoflurane anesthesia 


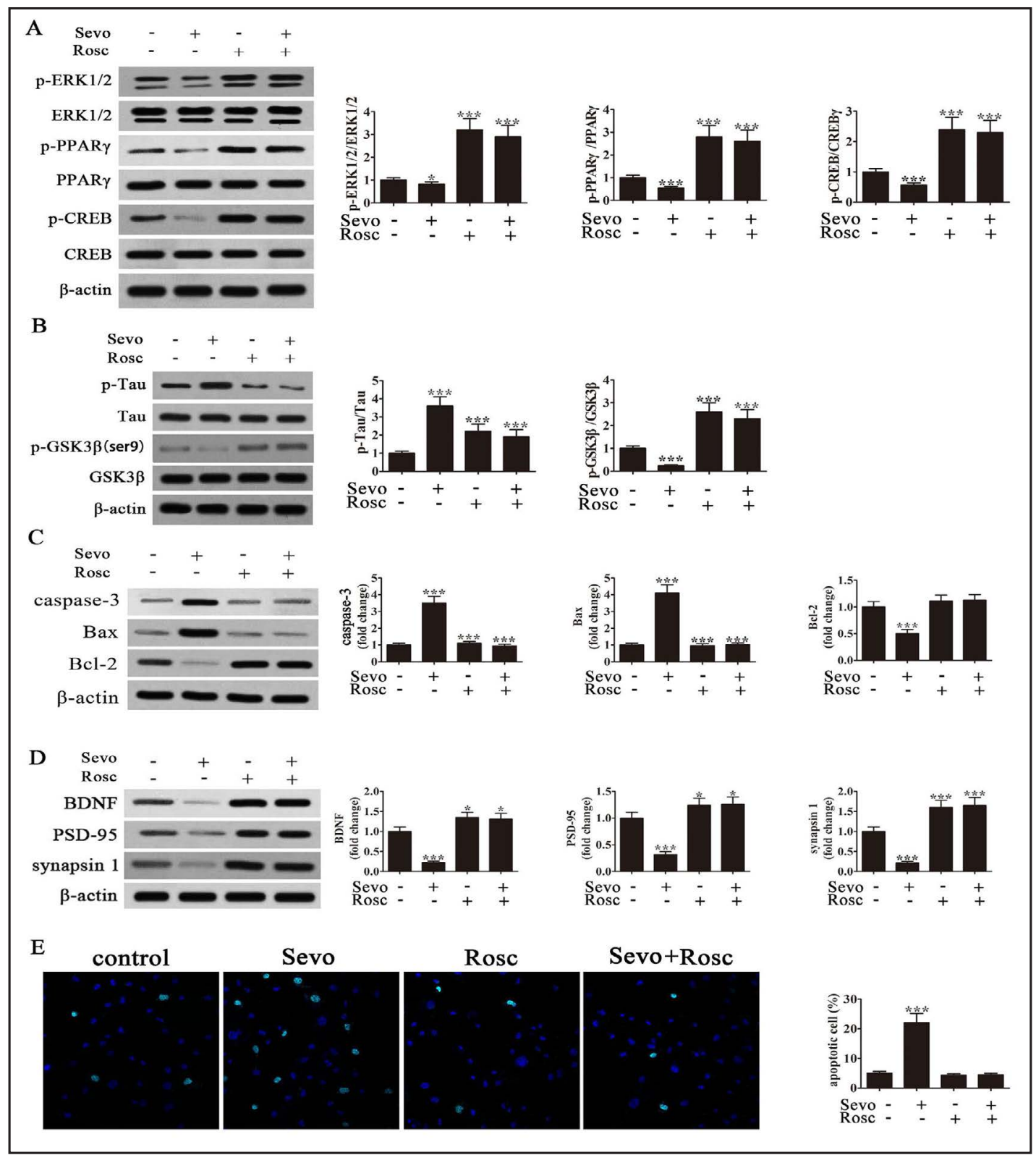

Fig. 5. CDK5 plays an important role in regulating the Tau/GSK3 $\beta$ and ERK/PPAR $\gamma / C R E B$ signaling pathways. Neurons were pretreated with $10 \mu \mathrm{M}$ CDK5 inhibitor roscovitine (Rosc) for $2 \mathrm{~h}$ before $4 \%$ sevoflurane treatment for $6 \mathrm{~h}$. (A) Levels of ERK/PPAR $\gamma /$ CREB signaling pathway components were detected by western blotting. Data represent mean $\pm \mathrm{SD}(\mathrm{n}=3)$. ${ }^{* * *} \mathrm{P}<0.001$ vs. control. (B) Levels of Tau/GSK3 $\beta$ signaling pathway components were detected by western blotting. Data represent mean $\pm \mathrm{SD}(\mathrm{n}=3) .{ }^{* * *} \mathrm{P}<0.001$ vs. control. (C) Expression of apoptosis-related proteins, as determined by western blotting. Data represent mean \pm SD ( $\mathrm{n}=3$ ). ${ }^{* * *} \mathrm{P}<0.001$ vs. control. (D) Expression of BDNF, PSD-95, and synapsin 1, as determined by western blotting. Data represent mean $\pm \mathrm{SD}(\mathrm{n}=3)$. ${ }^{* * *} \mathrm{P}<0.001$ vs. control. (E) Neuronal apoptosis was evaluated with the TUNEL assay. Data represent mean \pm SD $(n=10)$. ${ }^{* * *} \mathrm{P}<0.001$ vs. control.

suppressed the activation of ERK/PPAR $\gamma /$ CREB signaling, as determined by western blotting; this effect was reversed by inhibiting CDK5 with roscovitine (Fig. 5A). On the other hand, roscovitine treatment abrogated the sevoflurane-induced activation of Tau/ GSK3 $\beta$ signaling (Fig. 5B), as evidenced by reduced phosphorylation of Tau and increased phosphorylation of GSK3 $\beta$ at serine 9. Synapsin-1, BDNF, and PSD95 expression was also 
Fig. 6. Schematic timeline of the experimental design. Postnatal day (prefix P) when procedures/experiments were performed are indicated. IHC, immunohistochemistry; IF, immunofluorescence; MWM, Morris water maze test.
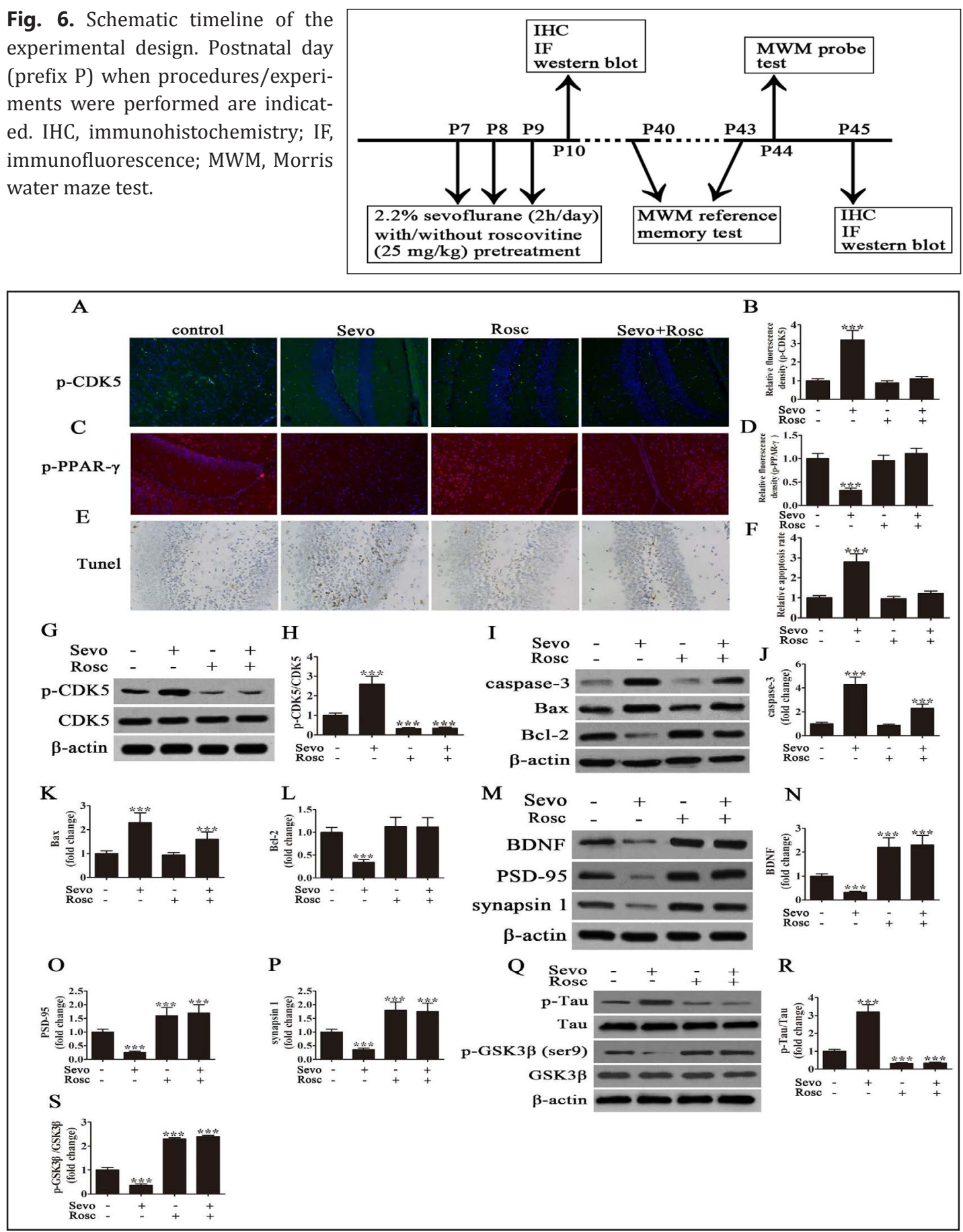

Fig. 7. Inhibition of CDK5 abrogates sevoflurane-induced neuronal apoptosis by stimulating ERK/PPAR- $\gamma /$ CREB and suppressing Tau/GS3K3 $\beta$ signaling. (A-D) Immunofluorescence detection of CDK5 (A, B) and PPAR- $\gamma(C, D)$ phosphorylation in hippocampus. Relative protein expression levels were determined based on fluorescence intensity. Data represent mean $\pm \mathrm{SD}(\mathrm{n}=10)$. ${ }^{* * *} \mathrm{P}<0.001$ vs. control. (E, F) Immunohistochemical detection of neuronal apoptosis with the TUNEL assay. Relative apoptosis rates were determined from cell counts. Data represent mean $\pm \mathrm{SD}(\mathrm{n}=10)$. ${ }^{* *} \mathrm{P}<0.001$ vs. control. $(\mathrm{G}, \mathrm{H})$ Detection of CDK5 phosphorylation by western blotting. Data represent mean $\pm \mathrm{SD}(\mathrm{n}=10)$. ${ }^{* * *} \mathrm{P}<0.001$ vs. control. (I-P) Expression of apoptosis-related proteins (I-L) and neuronal factors (M-P), as determined by western blotting. Data represent mean $\pm \mathrm{SD}(\mathrm{n}=10)$. ${ }^{* *} \mathrm{P}<0.001$ vs. control. $(\mathrm{Q}-\mathrm{S})$ Western blot detection of Tau $(\mathrm{Q}, \mathrm{R})$ and GS3K3 $3(\mathrm{Q}, \mathrm{S})$ phosphorylation in hippocampus. Data represent mean $\pm \mathrm{SD}(\mathrm{n}=10) .{ }^{* * *} \mathrm{P}<0.001$ vs. control. 


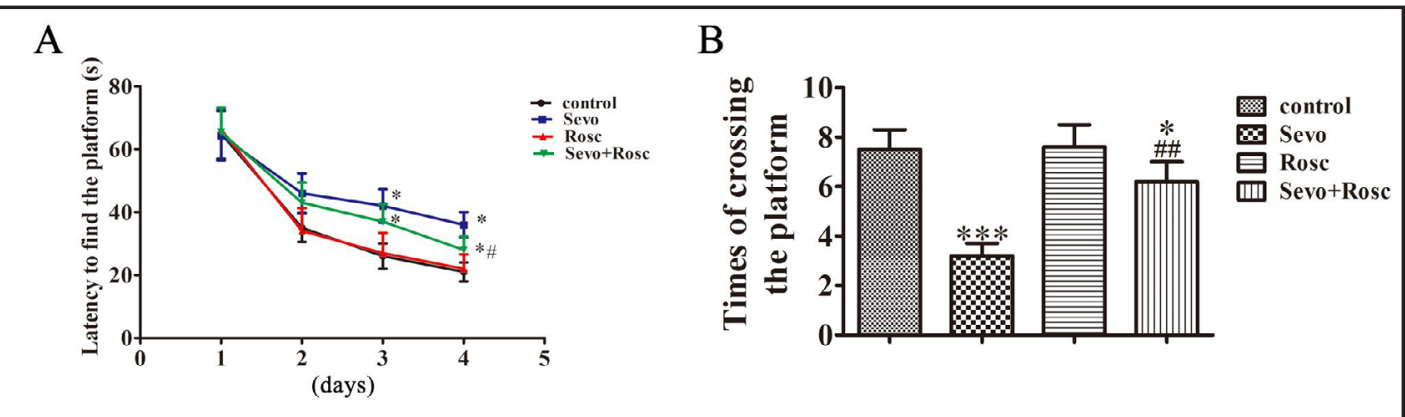

Fig. 8. CDK5 inhibition abrogates sevoflurane-induced cognitive impairment. (A) Mice in the sevoflurane treatment group exhibited a longer escape latency than control animals. CDK5 inhibition decreased the escape latency. Data represent mean $\pm \mathrm{SD}(\mathrm{n}=10)$. ${ }^{*} \mathrm{P}<0.05$ vs. control; ${ }^{*} \mathrm{P}<0.05$ vs. sevoflurane treatment group. (B) Number of platform crossings was decreased in the sevoflurane treatment group but was increased by CDK5 inhibition relative to the control group. Data represent mean $\pm \mathrm{SD}(\mathrm{n}=10)$. ${ }^{*} \mathrm{P}<0.05$, ${ }^{* * *} \mathrm{P}<0.001$ vs. control; ${ }^{\# \#} \mathrm{P}<0.01$ vs. sevoflurane treatment group.

upregulated by CDK5 inhibition (Fig. 5D). Meanwhile, caspase-3 and Bax expression was decreased and Bcl-2 expression was increased under these conditions (Fig. 5C). Consistent with these observations, immunofluorescence analysis showed a reduction in the apoptotic ratio by roscovitine treatment. These findings indicate that sevoflurane-induced cognitive impairment relative to CDK5 activation, and inhibiting CDK5 provides neuroprotection against the cytotoxicity of sevoflurane anesthesia.

\section{CDK5 inhibition prevents sevoflurane-induced neuronal injury in vivo}

We carried out a time-course experiment to analyze the effects of postnatal sevoflurane exposure in mice (Fig. 6). Postnatal mice were exposed to $2.2 \%$ sevoflurane for $2 \mathrm{~h}$ per day on days 7, 8, and 9. The hippocampal tissue was harvested on days 10 and 45 for analysis.

Roscovitine treatment suppressed sevoflurane-induced CDK5 phosphorylation (Fig. 7A) but increased PPAR $\gamma$ activation (Fig. 7B) in the hippocampus, as determined by immunocytochemistry. These observations were confirmed by western blotting (Fig. 7G, $\mathrm{H})$. Roscovitine induced CDK5, Tau and GSK3 $\beta$ activation inhibition reversed sevofluraneinduced neuronal apoptosis (Fig. 7C, I-L, Q-S), as evidenced by upregulation of Bcl-2 and downregulation of caspase- 3 and Bax. In addition, roscovitine treatment abolished the suppression of synapsin-1, BDNF, and PSD95 expression resulting from sevoflurane exposure (Fig. 7M-P). These findings indicate that inhibiting CDK5 blocks Tau/GSK3 $\beta$ and activates ERK/PPAR $\gamma / C R E B$ signaling in neurons in vivo and thereby prevents sevoflurane-induced apoptosis.

CDK5 inhibition abrogates sevoflurane-induced cognitive impairment

To assess the behavioral consequences of inhibiting CDK5 in sevoflurane-treated mice, spatial learning and memory were assessed with the MWM (Fig. 8A). Mice exposed to sevoflurane showed longer escape latency than control animals. Furthermore, CDK5 suppression by roscovitine treatment decreased the percentage of time spent by mice in the target quadrant. During the spatial probe test, the number of platform crossings was decreased in the sevoflurane treatment group, but increased relative to controls upon roscovitine treatment (Fig. 8B). Thus, blocking CDK5 activation reduces sevoflurane-induced cognitive impairment.

\section{Discussion}

Sevoflurane have been widely applied in clinical and exposed many problems [26]. The results of this study provide evidence for a novel mechanism underlying sevoflurane 
Fig. 9. Proposed mechanism by which sevoflurane induces neuronal apoptosis via CDK5.

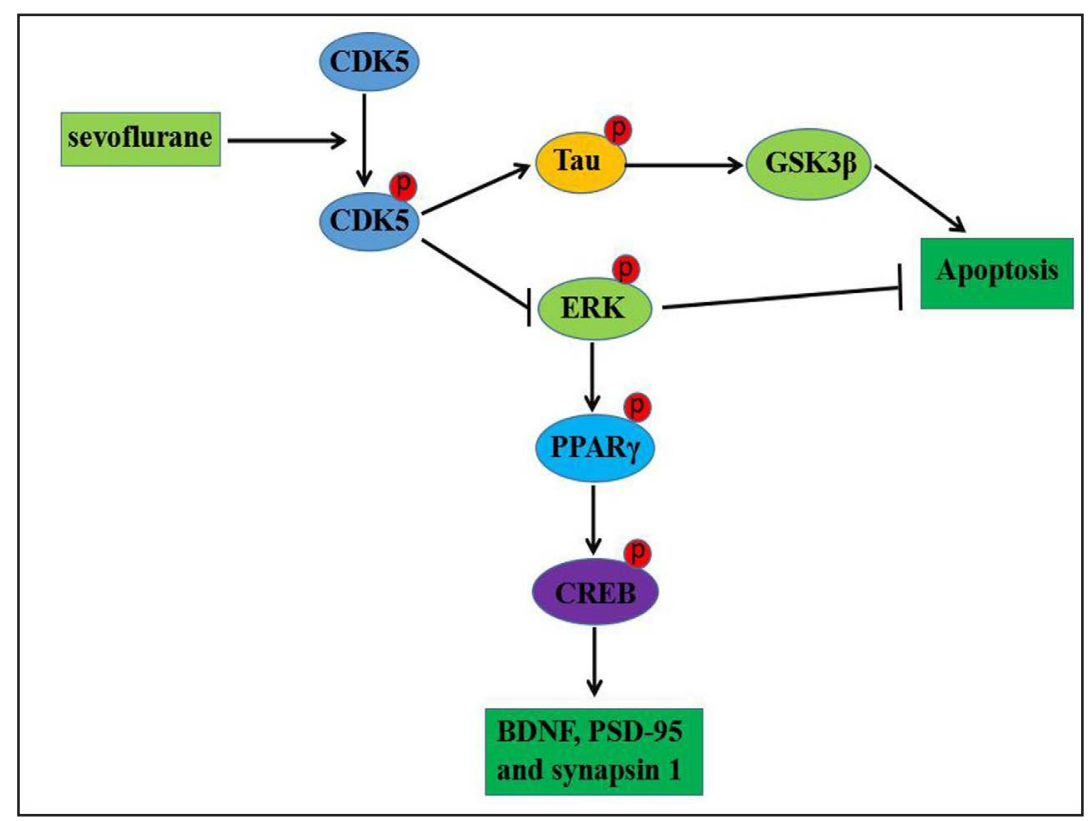

induced cognitive function affects phosphorylation of all substrates listed including CDK5 (Fig. 9). Sevoflurane anesthesia activates Tau/GSK3 $\beta$ signaling via CDK5, leading to neuronal apoptosis. The ERK/PPAR $\gamma /$ CREB signaling cascade, which normally exerts a protective effect in neurons, was inhibited by sevoflurane. CDK5 plays an important role in modulating the crosstalk between Tau/GSK3 $\beta$ and ERK/PPAR $\gamma /$ CREB pathways; inhibiting CDK5 activation by treatment with roscovitine blocked Tau/GSK3 $\beta$ signaling and abrogated the suppression of ERK/PPAR $\gamma / \mathrm{CREB}$, resulting in improved cognitive function.

We previously showed that sevoflurane causes cognitive impairment in young mice by stimulating the apoptosis of hippocampal neurons. We also found that upregulation of phosphorylated ERK1/2 promotes neuronal survival [18]. In the present study, we found that ERK1/2 phosphorylation is regulated by CDK5 and is inhibited by sevofluraneinduced CDK5 activation, in agreement with a previous report [27]. Activated ERK1/2 can phosphorylate and activate PPAR $\gamma$ and CREB and thereby abrogate sevoflurane-induced, CDK5-mediated neuronal injury. PPAR $\gamma$ has anti-inflammatory, -oxidative, and -apoptotic properties $[20,28]$. We found here that CDK5 activation promotes Tau phosphorylation and activates GSK3 $\beta$ signaling, which in turn enhanced neuronal injury and cognitive dysfunction caused by sevoflurane exposure [17]. We propose that inhibiting CDK5 has protective effects following sevoflurane exposure. Roscovitine treatment increased synapsin-1, BDNF, and PSD95 expression in hippocampal neurons, which may explain the observed improvement in cognitive function.

Learning and memory are complex processes that are influenced by many factors. Neuronal death via apoptosis can cause deficits in learning and memory consolidation. Anesthesia-induced cognitive impairment has been linked to neural apoptosis resulting from CDK5 activation in the central nervous system [29-31]. Thus, CDK5 is a potential therapeutic target for treating anesthesia-induced cognitive dysfunction, although additional studies are needed in order to verify the clinical relevance of the present findings.

\section{Conclusion}

In summary, our results provide insight into the mechanisms underlying the neurotoxicity of sevoflurane and can serve as a basis for the development of therapeutic approaches for mitigating the damaging effects of anesthesia in pediatric patients. 


\section{Cellular Physiology Cell Physiol Biochem 2017;44:423-435 and Biochemistry Published onIne: November 15, $2016 \quad \begin{aligned} & \text { (c) } 2017 \text { The Author(s). Published by S. Karger AG, Basel } \\ & \text { www.karger.com/cpb }\end{aligned}$}

Liu et al.: The Effect of CDK5 to Sevoflurane-Induced Cognitive Dysfunction

\section{Acknowledgements}

This study was supported by National Natural Science Foundation (81600934), Natural Science Foundation of Shanghai, China (16ZR1432200), Medicine guidance of Science and Technology Commission of Shanghai Municipality (16411967700 ), awarded to Jianhui Liu. None of the funders had participated in the analysis and interpretation of data, writing of the paper or the submission of the article for publication. The authors would like to thank the Department of Anesthesiology and psychology at Shanghai Tongji hospital affiliated to Tongji University, China, for performing the neuropsychological analyses and assisting in the data analysis and interpretation.

No funding received for the work from any of the following organizations: National Institutes of Health (NIH), Wellcome Trust, Howard Hughes Medical Institute (HHMI), and all other financial support, including departmental or institutional funding.

\section{Disclosure Statement}

The authors declare no competing interests.

\section{References}

1 Young C, Jevtovic-Todorovic V, Qin YQ Tenkova T, Wang H, Labruyere J, Olney JW: Potential of ketamine and midazolam, individually or in combination, to induce apoptotic neurodegeneration in the infant mouse brain. Br J Pharmacol 2005;146:189-197.

-2 Straiko MM, Young C, Cattano D, Creeley CE, Wang H, Smith DJ, Johnson SA, Li ES, Olney JW: Lithium protects against anesthesia-induced developmental neuroapoptosis. Anesthesiology 2009;110:862-868.

-3 Pellegrini L, Bennis Y, Velly L, Grandvuillemin I, Pisano P, Bruder N, Guillet B: Erythropoietin protects newborn rat against sevoflurane-induced neurotoxicity. Paediatr Anaesth 2014;24:749-759.

4 Lu Y, Huang Y, Jiang J, Hu R, Yang Y, Jiang H, Yan J: Neuronal apoptosis may not contribute to the longterm cognitive dysfunction induced by a brief exposure to $2 \%$ sevoflurane in developing rats. Biomed Pharmacother 2016;78:322-328.

5 Jia ZM, Hao HN, Huang ML, Ma DF, Jia XL, Ma B: Influence of dexmedetomidine to cognitive function during recovery period for children with general anesthesia. Eur Rev Med Pharmacol Sci 2017;21:1106-1111.

6 Aun CS, McBride C, Lee A, Lau AS, Chung RC, Yeung CK, Lai KY, Gin T: Short-Term Changes in Postoperative Cognitive Function in Children Aged 5 to 12 Years Undergoing General Anesthesia: A Cohort Study. Medicine (Baltimore) 2016;95:e3250.

-7 Squire LR: Memory and the hippocampus: a synthesis from findings with rats, monkeys, and humans. Psychol Rev 1992;99:195-231.

8 Hu ZY, Jin HY, Xu LL, Zhu ZR, Jiang YL, Seal R: Effects of sevoflurane on the expression of tau protein mRNA and Ser396/404 site in the hippocampus of developing rat brain. Paediatr Anaesth 2013;23:1138-1144.

-9 Hu N, Guo D, Wang H, Xie K, Wang C, Li Y, Yu Y, Wang G: Involvement of the blood-brain barrier opening in cognitive decline in aged rats following orthopedic surgery and high concentration of sevoflurane inhalation. Brain Res 2014;1551:13-24.

10 Zheng JW, Meng B, Li XY, Lu B, Wu GR, Chen JP: NF-kappaB/P65 signaling pathway: a potential therapeutic target in postoperative cognitive dysfunction after sevoflurane anesthesia. Eur Rev Med Pharmacol Sci 2017;21:394-407.

11 Yufune S, Satoh Y, Akai R, Yoshinaga Y, Kobayashi Y, Endo S, Kazama T: Suppression of ERK phosphorylation through oxidative stress is involved in the mechanism underlying sevoflurane-induced toxicity in the developing brain. Sci Rep 2016;6:21859.

12 Zheng YL, Zhang X, Fu HX, Guo M, Shukla V, Amin ND, E J, Bao L, Luo HY, Li B, Lu XH, Gao YC: Knockdown of Expression of Cdk5 or p35 (a Cdk5 Activator) Results in Podocyte Apoptosis. PLoS One 2016;11:e0160252.

13 Gutierrez-Vargas JA, Munera A, Cardona-Gomez GP: CDK5 knockdown prevents hippocampal degeneration and cognitive dysfunction produced by cerebral ischemia. J Cereb Blood Flow Metab 2015;35:1937-1949. 


\section{Cellular Physiology Cell Physiol Biochem 2017;44:423-435 \begin{tabular}{l|l} 
and Biochemistry Publisher 10.1159/000485008 & $\begin{array}{l}\text { (c) } 2017 \text { The Author(s). Published by S. Karger AG, Basel } \\
\text { www.karger.com/cpb }\end{array}$
\end{tabular}

14 Banks AS, McAllister FE, Camporez JP, Zushin PJ, Jurczak MJ, Laznik-Bogoslavski D, Shulman GI, Gygi SP, Spiegelman BM: An ERK/Cdk5 axis controls the diabetogenic actions of PPARgamma. Nature 2015;517:391-395.

15 Zhang Z, Yuan H, Zhao H, Qi B, Li F, An L: PPARgamma activation ameliorates postoperative cognitive decline probably through suppressing hippocampal neuroinflammation in aged mice. Int Immunopharmacol 2017;43:53-61.

-16 Gassowska M, Baranowska-Bosiacka I, Moczydlowska J, Tarnowski M, Pilutin A, Gutowska I, Struzynska L, Chlubek D, Adamczyk A: Perinatal exposure to lead (Pb) promotes Tau phosphorylation in the rat brain in a GSK-3beta and CDK5 dependent manner: Relevance to neurological disorders. Toxicology 2016;347349:17-28.

17 Tao G, Zhang J, Zhang L, Dong Y, Yu B, Crosby G, Culley DJ, Zhang Y, Xie Z: Sevoflurane induces tau phosphorylation and glycogen synthase kinase 3 beta activation in young mice. Anesthesiology 2014;121:510-527.

18 Liu J, Zhang X, Zhang W, Gu G, Wang P: Effects of Sevoflurane on Young Male Adult C57BL/6 Mice Spatial Cognition. PLoS One 2015;10:e0134217.

19 Wang Y, Wang W, Li D, Li M, Wang P, Wen J, Liang M, Su B, Yin Y: IGF-1 alleviates NMDA-induced excitotoxicity in cultured hippocampal neurons against autophagy via the NR2B/PI3K-AKT-mTOR pathway. J Cell Physiol 2014;229:1618-1629.

20 Wu JS, Tsai HD, Cheung WM, Hsu CY, Lin TN: PPAR-gamma Ameliorates Neuronal Apoptosis and Ischemic Brain Injury via Suppressing NF-kappaB-Driven p22phox Transcription. Mol Neurobiol 2016;53:36263645 .

-21 Makdissy N, Haddad K, Mouawad C, Popa I, Younsi M, Valet P, Brunaud L, Ziegler O, Quilliot D: Regulation of SREBPs by Sphingomyelin in Adipocytes via a Caveolin and Ras-ERK-MAPK-CREB Signaling Pathway. PLoS One 2015;10:e0133181.

-22 Ramagiri S, Taliyan R: Remote limb ischemic post conditioning during early reperfusion alleviates cerebral ischemic reperfusion injury via GSK-3beta/CREB/ BDNF pathway. Eur J Pharmacol 2017;803:84-93.

23 Duan Y, Wang Z, Zhang H, He Y, Fan R, Cheng Y, Sun G, Sun X: Extremely low frequency electromagnetic field exposure causes cognitive impairment associated with alteration of the glutamate level, MAPK pathway activation and decreased CREB phosphorylation in mice hippocampus: reversal by procyanidins extracted from the lotus seedpod. Food Funct 2014;5:2289-2297.

24 Wu J, Zhang M, Li H, Sun X, Hao S, Ji M, Yang J, Li K: BDNF pathway is involved in the protective effects of SS-31 on isoflurane-induced cognitive deficits in aging mice. Behav Brain Res 2016;305:115-121.

25 Plattner F, Hernandez A, Kistler TM, Pozo K, Zhong P, Yuen EY, Tan C, Hawasli AH, Cooke SF, Nishi A, Guo A, Wiederhold T, Yan Z, Bibb JA: Memory enhancement by targeting Cdk5 regulation of NR2B. Neuron 2014;81:1070-1083.

26 Xu Z, Yu J, Wu J, Qi F, Wang H, Wang Z, Wang Z: The Effects of Two Anesthetics, Propofol and Sevoflurane, on Liver Ischemia/Reperfusion Injury. Cell Physiol Biochem 2016;38(4):1631-42.

27 Song H, Kim W, Choi JH, Kim SH, Lee D, Park CH, Kim S, Kim DY, Kim KT: Stress-induced nuclear translocation of CDK5 suppresses neuronal death by downregulating ERK activation via VRK3 phosphorylation. Sci Rep 2016;6:28634.

-28 Helmy MM, Helmy MW, El-Mas MM: Additive Renoprotection by Pioglitazone and Fenofibrate against Inflammatory, Oxidative and Apoptotic Manifestations of Cisplatin Nephrotoxicity: Modulation by PPARs. PLoS One 2015;10:e0142303.

29 She H, Mao Z: Study of ATM Phosphorylation by Cdk5 in Neuronal Cells. Methods Mol Biol 2017;1599:363374.

30 Xia Y, Xu H, Jia C, Hu X, Kang Y, Yang X, Xue Q Tao G, Yu B: Tanshinone IIA Attenuates Sevoflurane Neurotoxicity in Neonatal Mice. Anesth Analg 2017;124:1244-1252.

-31 Hyun HW, Min SJ, Kim JE: CDK5 inhibitors prevent astroglial apoptosis and reactive astrogliosis by regulating PKA and DRP1 phosphorylations in the rat hippocampus. Neurosci Res 2017;119:24-37. 